OPEN ACCESS

Edited by:

Qingli Dong,

University of Shanghai for Science and Technology, China

Reviewed by:

M. Oves,

King Abdulaziz University,

Saudi Arabia

Zhanmin Liu,

Shanghai University, China

Tianbao Yang

United States Department

of Agriculture, United States

*Correspondence:

Zhaoxin Lu

fmb@njau.edu.cn

Specialty section: This article was submitted to

Food Microbiology,

a section of the journal

Frontiers in Microbiology

Received: 19 April 2018 Accepted: 19 October 2018 Published: 08 November 2018

Citation:

Shi J, Zhu X, Lu Y, Zhao H, Lu F and $L u Z$ (2018) Improving Iturin

A Production of Bacillus amyloliquefaciens by Genome Shuffling and Its Inhibition Against Saccharomyces cerevisiae in Orange Juice. Front. Microbiol. 9:2683 doi: 10.3389/fmich.2018.02683

\section{Improving Iturin A Production of Bacillus amyloliquefaciens by Genome Shuffling and Its Inhibition Against Saccharomyces cerevisiae in Orange Juice}

\author{
Juran Shi', Xiaoyu Zhu', Yingjian Lu' ${ }^{2}$, Haizhen Zhao', Fengxia $L u^{1}$ and Zhaoxin Lu ${ }^{1 *}$ \\ ' College of Food Science and Technology, Nanjing Agricultural University, Nanjing, China, ${ }^{2}$ Department of Nutrition \\ and Food Science, University of Maryland, College Park, MD, United States
}

Genome shuffling is an effective method for the rapid improvement of the production of secondary metabolites. This study used the principle of gene shuffling to enhance the yield of iturin A produced by Bacillus amyloliquefaciens LZ-5. Improvements in lipopeptide yield were evident among four strains subjected to recursive protoplast fusion. The four strains were obtained through mutagenesis processes: nitrosoguanidine, ultraviolet irradiation, and atmospheric and room temperature plasma. A high yield strain with $179.22 \mathrm{mg} / \mathrm{l}$ of iturin A was obtained after two rounds of genome shuffling, which was a 2.03-fold increase compared with the wild strain. To evaluate the efficacy of iturin A for control of spoilage yeast in food, the anti-yeast efficacy of iturin A was evaluated in orange juice incubated with Saccharomyces cerevisiae. The juice treated with $0.76 \mathrm{mg} / \mathrm{ml}$ iturin A showed a significant $(p<0.05)$ control on yeast population during the storage, similar to that of the $0.30 \mathrm{mg} / \mathrm{ml}$ natamycin. In addition, iturin A showed a tiny effect on chemical-physical characteristics of orange juice. Our results provide a basis for the application of antimicrobial lipopeptide in juice products.

Keywords: genome shuffling, iturin, preservation, orange juice, Saccharomyces cerevisiae, Bacillus amyloliquefaciens

\section{INTRODUCTION}

Bacillus strains can produce many kinds of secondary metabolites including antimicrobial lipopeptides synthesized by a complex multifunctional enzyme system. They are also reported to have a genomic basis for the biosynthesis of polyketide or nonribosomal peptide derivatives due to the presence of polyketide synthases (PKSs) and nonribosomal peptide-synthetase (NRPS). Iturin $\mathrm{A}$, which is a cyclo-lipopeptide containing seven residues of $\alpha$-amino acids (L-Asn-D-TyrD-Asn-L-Gln-L-Pro-D-Asn-L-Ser-) and one residue of a $\beta$-amino acid, is an essential ingredient of 
the antimicrobial substance. Because of its strong antifungal activity against an extensive range of plant pathogens, iturin $\mathrm{A}$ is applied the most widely in biological control of plant diseases (Leclere et al., 2005). Moreover, antimicrobial lipopeptides are also used in the cosmetic industries (Kanlayavattanakul and Lourith, 2010), food (Bie et al., 2005). And they can enhance oil recovery (Schaller et al., 2004) and improve the bioremediation of oil-contaminated sites (Mulligan et al., 2001). Iturin A is produced mainly by Bacillus amyloliquefaciens and B. subtilis, but its application is limited by low production.

During the last decade, researchers have made good efforts in improving the production of iturin A. The optimization of medium and culture conditions is in general use, and the screening of wild strains (Cho et al., 2009) with high yield is another critical method. But these rational methods and traditional techniques are inefficient (Grau et al., 2000). As the reach of shuffling technology from DNA fragments expands to the whole genome, genome shuffling is regarded as an alternative means to wild strain improvement. It could accelerate evolution without the need of sequence information. Genome shuffling is an efficient method that uses successive protoplasts fusion to recombine useful gene segment of parental strains into one single cell showing the desired phenotype (Biot-Pelletier and Martin, 2014). This approach was first reported by Zhang et al. (2002), who carried out two rounds of shuffling of Streptomyces fradiae, acquiring a sixfold increase in the production of tylosin in comparison with the parental strain. Additionally, genome shuffling is widely applied in sugar alcohol production with the improvement of yeast Pichia anomala (Zhang et al., 2015), the ethanol tolerance increase in Saccharomyces cerevisiae (Snoek et al., 2015), the butanol production enhancement of Clostridium acetobutylicum (Li et al., 2016), and the improvement of L-lactic acid production from the fusant of Lactobacillus delbrueckii and B. amyloliquefaciens (John et al., 2008).

The inherent acidity of fruit juices provides a strong defense to most bacterial species. However, several outbreaks of yeast infections have occurred recently. It is becoming a detrimental issue to fruit products as yeasts have tolerance to acidity (Aznar et al., 2015). According to the report, the spoilage of fresh pineapple juice is generally attributed to Pichia guilliermondii, P. fermentans, $P$. membranifaciens, Hanseniaspora uvarum, Candida stellata, Rhodotorula spp. (Bevilacqua et al., 2015). Moreover, S. cerevisiae and Schizosaccharomyces pombe can spoil most kinds of fruit juices and soft drinks (Malcolm, 2006). And many studies have taken $S$. cerevisiae as the primary focus in the microorganism control of orange juice (Loredo et al., 2015; Samani et al., 2015). The existence of this contamination will cause potential health hazards and serious economic losses. In general, the control of spoilage yeasts in food and beverage manufacturing is managed mainly by using some commercial food-grade chemical additives (Labbani et al., 2015) or thermal treatments. However, these measures may have harmful effects on human health or make changes in bioactive compounds present as well as any organoleptic changes. In the past decades, there is a growing popularity in finding alternatives, including vanillin, benzaldehyde, ferulic acid (Bevilacqua et al., 2015), and mentha oil (Tyagi and Malik, 2010). These alternatives are used to avoid the defect of conventional methods. Lastly, new natural anti-yeast compounds are still promoted for extending the shelf life of fruit juice and for avoiding microorganism infections.

The molecular structure of antimicrobial lipopeptide is of great interest because of their biological and physicochemical properties, which can be applicable in food, oil, and pharmaceutical industries (Meena and Kanwar, 2015). Up to now, antimicrobial lipopeptide is mostly considered as a biosurfactant for applications in food industry (Nitschke and Costa, 2007). It is used as emulsifiers in the processing of raw materials; in order to maintain texture, stability, and volume especially in baking. Furthermore, it helps with the emulsification of fat in order to control the aggregation of fat globules (Mandal et al., 2013). The existence of lipopeptides in fermented food products (Cho et al., 2009) was also regarded for their applications in food. On the contrary, there is little study on its antimicrobial activity in fruit juice, where there is an acid condition for lipopeptide stability. According to our knowledge, some kind of iturin exerts the activity of anti-yeast, including iturin A, bacillomycin F (Mhammedi et al., 1982), mycosubtilin (Leclere et al., 2005), etc. In that respect, there is a potential application in the control of yeast spoilage in food. Notably, iturin is natural and would replace the use of chemical preservatives. In the present study, we tried to use the mean of genome shuffling to increase the yield of iturin A from B. amyloliquefaciens. Moreover, we intend to investigate its potential in the preservation of orange juice against $S$. cerevisiae and evaluate its effect on the chemical-physical properties of juice.

\section{MATERIALS AND METHODS}

\section{Strains and Culture Conditions}

The wild strain, B. amyloliquefaciens LZ-5 was isolated from Chinese honey. Three mutagenesis methods, nitrosoguanidine (NTG), ultraviolet irradiation (UV), and atmospheric and room temperature plasma (ARTP) were used to acquire four mutants. The average antimicrobial lipopeptide production of these mutants was $23.1 \%$ higher than the wild strain and they were used as the initial strains. The mutants were maintained in the standard potato dextrose agar (PDA) media at $37^{\circ} \mathrm{C}$, and the inoculums were prepared in potato dextrose broth (PDB) media shaking at $180 \mathrm{rpm}$ at $37^{\circ} \mathrm{C}$ for $12 \mathrm{~h}$. The modified landy medium (glucose $42 \mathrm{~g} / \mathrm{l}, \mathrm{L}$-sodium glutamate $14 \mathrm{~g} / \mathrm{l}, \mathrm{MgSO}_{4} 0.5$ g/l, KCl 0.5 g/l, $\mathrm{KH}_{2} \mathrm{PO}_{4} 1.0 \mathrm{~g} / \mathrm{l}, \mathrm{FeSO}_{4} 0.15 \mathrm{mg} / \mathrm{l}, \mathrm{MnSO}_{4} 5.0$ $\mathrm{mg} / \mathrm{l}, \mathrm{CuSO}_{4} 0.16 \mathrm{mg} / \mathrm{l}$ ) was used as fermentation medium. SMM (sucrose $171.14 \mathrm{~g} / \mathrm{l}, \mathrm{MgCl}_{2} \cdot 6 \mathrm{H}_{2} \mathrm{O} 4.07 \mathrm{~g} / \mathrm{l}$, and maleic acid 2.32 $\mathrm{g} / \mathrm{l})$ was taken as a stabilizer. The protoplast was maintained on hypertonic regeneration medium (RM) medium (PDA with $0.6 \mathrm{~mol} / \mathrm{l} \mathrm{NaCl}$ ) for cell regeneration. Lysozyme was purchased from Sigma and dissolved in PSB, sterilized by filtration through a $0.22 \mu \mathrm{m}$ membrane filter. Polyethylene glycol (PEG) 6000 (40\%) was prepared in SMM. S. Cerevisiae (AS2.114), preserved in PDB media with $20 \%(\mathrm{v} / \mathrm{v})$ glycerol at $-20^{\circ} \mathrm{C}$, was the indicator to evaluate the effect of iturin A. Before use, the yeast strain was cultured in $\mathrm{PDB}$ media at $28^{\circ} \mathrm{C}$ for $24 \mathrm{~h}$ at $180 \mathrm{rpm}$. In broth 
microdilution assay, $S$. cerevisiae was cultured in YPD (yeast extract $10 \mathrm{~g} / \mathrm{l}$, peptone $20 \mathrm{~g} / \mathrm{l}$, glucose $20 \mathrm{~g} / \mathrm{l}$ ) media. All other chemicals used in this work were of analytical grade.

\section{Procedure of Genome Shuffling}

The parent library was constructed by UV, NTG, and ARTP mutagenesis methods and four strains named U-36, N-22, A-8, and A-61 were collected in the previous work as the initial strains. The initial strains were cultured for $8 \mathrm{~h}$ at $37^{\circ} \mathrm{C}$ in $50 \mathrm{ml} \mathrm{PDB}$ medium. When the optical density at $600 \mathrm{~nm}\left(\mathrm{OD}_{600}\right)$ reached $1.6 \sim 1.8$, cells were harvested by centrifugation, washed twice with sterile double-distilled water and suspended in SMM in a final concentration of $10^{7}$ cells $/ \mathrm{ml}$. The cell suspensions were incubated in PSB containing $0.2 \mathrm{mg} / \mathrm{ml}$ lysozyme in a water bath at $37^{\circ} \mathrm{C}$ for $10 \mathrm{~min}$. After the enzymatic digestion of the cytoderm, cells were washed twice and re-suspended in PSB. The formation of protoplasts could be judged by light microscopy.

The equal number of protoplasts from different populations were mixed and divided into two fractions for inactivity. One fraction was placed under a preheated $30 \mathrm{~W}$ UV lamp at a vertical distance of $15 \mathrm{~cm}$ and irradiated for $60 \mathrm{~min}$. The other was put in a water bath at $100^{\circ} \mathrm{C}$ for $30 \mathrm{~min}$. All of the inactivated protoplasts were mixed in the same ratio, washed twice, centrifuged and re-suspended in $0.5 \mathrm{ml} \mathrm{SMM}$. After the addition of $4.5 \mathrm{ml} 40 \%(\mathrm{v} / \mathrm{v})$ PEG 6000 , the suspension was shaken gently at room temperature for $5 \mathrm{~min}$ to allow protoplasts fusion. After adding $5 \mathrm{ml}$ PSB to terminate the reaction, the fused protoplasts were washed, centrifuged and re-suspended in $1 \mathrm{ml}$ PSB. The serial dilutions of the suspension were spread on $\mathrm{RM}$ plates and incubated for $36 \mathrm{~h}$ at $37^{\circ} \mathrm{C}$. The antimicrobial lipopeptide productivity was determined by the agar-diffusion method employing S. cerevisiae as an indicating strain. After preliminary screening, the production of iturin $\mathrm{A}$ in selected strains was analyzed by HPLC (AGILENT 1100 series). Three strains with highest antimicrobial lipopeptide production were obtained as start strains for the next fusion. Two successive rounds of protoplast fusion were then carried out.

\section{Determination of Iturin A}

The bioactive substance was isolated by acid precipitation. Activated culture of B. amyloliquefaciens LZ-5 was incubated $(5 \%, \mathrm{v} / \mathrm{v})$ in modified landy medium, and shaken at $180 \mathrm{rpm}$ at $30^{\circ} \mathrm{C}$ for $72 \mathrm{~h}$. And then the fermentation broth was centrifuged at $10,000 \mathrm{~g}, 4^{\circ} \mathrm{C}$ for $20 \mathrm{~min}$. The supernatant collected was adjusted to $\mathrm{pH} 2$ using $6 \mathrm{~N} \mathrm{HCl}$, followed by centrifugation at $8000 \mathrm{~g}$ for $10 \mathrm{~min}$. The supernatant was discarded and the precipitated lipopeptides were extracted for three times by anhydrous ethanol. To study the bioactive substance purified from fermentation broth, Iturin A was identified and measured by reversed-phase high-performance liquid chromatography (HPLC; C18 column, ODS $4.6 \mathrm{~mm} \times 250 \mathrm{~mm}$, AGILENT 1100 series) with UV detectors and HPLC-MS/MS (Thermo Electron Corporation, San Jose, CA, United States). The eluent was methyl cyanides at a flow rate of $0.6 \mathrm{ml} / \mathrm{min}$. The injection volume of the sample was $20 \mu \mathrm{L}$. For its application in the orange juice, the bioactive substance was decolorized using $0.5 \%(\mathrm{w} / \mathrm{v})$ activated carbon and gently shaken for $4 \mathrm{~h}$, and then it was concentrated and freeze-dried. Then antiyeast test of Iturin A in Orange Juice was carried out as following.

\section{Treatment of Orange Juice With Iturin A}

The commercial orange juice used in this study was purchased from a local store in Nanjing, Jiangsu province, China. $50 \mathrm{ml}$ of orange juice was placed in sterilized glass vials. The suspension of $S$. cerevisiae was added to orange juice resulting in final concentration of $10^{3} \mathrm{cfu} / \mathrm{ml}$. The iturin A was dissolved in $0.5 \mathrm{ml}$ ethanol and then mixed with orange juice resulting in three final concentrations of $0.13,0.38$, and $0.76 \mathrm{mg} / \mathrm{ml}$, respectively. Natamycin was added into the orange juice at the final concentration of $0.3 \mathrm{mg} / \mathrm{ml}$. Six treatments, including a blank control (juice plus sterile water), negative control (juice plus $10^{3} \mathrm{cfu} / \mathrm{ml} \mathrm{S}$. cerevisiae and sterile water), Natamycin (juice plus $10^{3} \mathrm{cfu} / \mathrm{ml} \mathrm{S}$. cerevisiae and $0.3 \mathrm{mg} / \mathrm{ml}$ natamycin), $\mathrm{C} 1$ (juice plus $10^{3} \mathrm{cfu} / \mathrm{ml} \mathrm{S}$. cerevisiae and $0.13 \mathrm{mg} / \mathrm{ml}$ iturin A), C2 (juice plus $10^{3} \mathrm{cfu} / \mathrm{ml} \mathrm{S.} \mathrm{cerevisiae} \mathrm{and} 0.38 \mathrm{mg} / \mathrm{ml}$ iturin A), and C3 (juice plus $0.76 \mathrm{mg} / \mathrm{ml}$ iturin A and $10^{3} \mathrm{cfu} / \mathrm{ml}$ S. cerevisiae), were set in this study. The prepared orange juice was stored at $25^{\circ} \mathrm{C}$ for 10 day and the quality of samples were detected on $0,2 \mathrm{nd}, 4$ th, 6 th, 8 th, and 10th day, respectively.

\section{Effect of Iturin A on Yeast Growth}

$0.1 \mathrm{ml}$ aliquot of each sample was serially diluted and plated on PDA. The plates were incubated for $24 \mathrm{~h}$ at $28^{\circ} \mathrm{C}$ and the colonies were counted. The efficacy of different concentration of iturin A and natamycin was indicated by the variation of the inoculated yeast strains with storage time, which is expressed in log $\mathrm{cfu} / \mathrm{ml}$ (Tyagi et al., 2013).

\section{Physical-Chemical Characteristics of the Stored Orange Juice}

A set of the orange juice samples were incubated with S. cerevisiae of $10^{3} \mathrm{cfu} / \mathrm{ml}$ and the total acidity,vitamin C, total soluble solid and browning index were measured. The total acidity was assessed by direct titration referring to the modified method described by Peter et al. (2012). $5 \mathrm{ml}$ of juice was diluted with ultrapure water up to $100 \mathrm{ml}$. Then,a volume of $25 \mathrm{ml}$ solution was placed in an erlenmeyer flask and two drops of phenolphthalein solution $1 \%$ were added. The mixture was titrated with $0.1 \mathrm{~N} \mathrm{NaOH}$ solution, until the pink color of the solution persisted for at least $1 \mathrm{~min}$. Titratable acidity was expressed as grams malic acid per $100 \mathrm{ml}$ juice.

The vitamin $\mathrm{C}$ was measured using the 2,6dichloroindophenol titrimetric method according to Masamba and Nguyen (2008). A quantity of $5 \mathrm{ml}$ juice was diluted with $2 \%$ solution of oxalic acid up to $100 \mathrm{ml}$ and the mixture was centrifuged at $4,000 \mathrm{rpm}$ for $5 \mathrm{~min} .10 \mathrm{ml}$ of supernatant was titrated with the standard solution 2,6-dichloroindophenol $(0.1 \%)$ until the pink color of the solution persisted for at least $1 \mathrm{~min}$. The vitamin $\mathrm{C}$ content was expressed as milligrams ascorbic acid per $100 \mathrm{ml}$ 

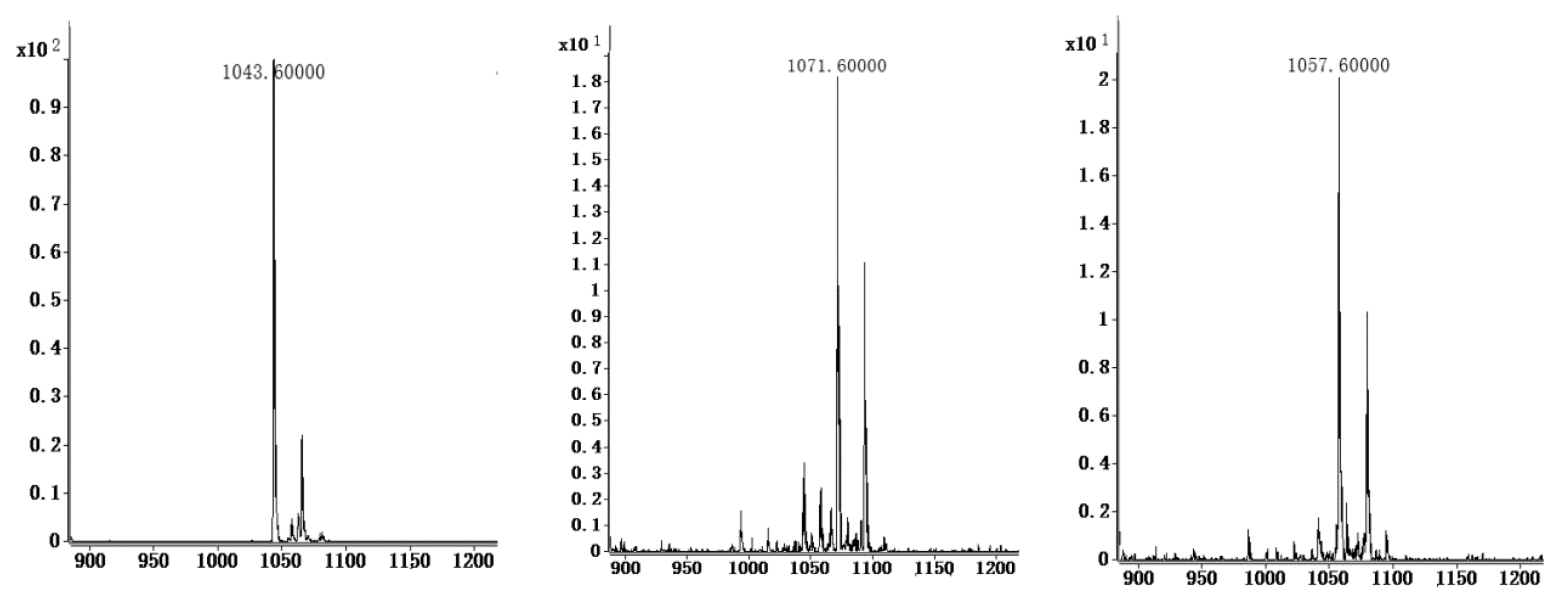

FIGURE 1 | The LC-MS spectrum of iturin A homolog from Bacillus amyloliquefaciens LZ-5.

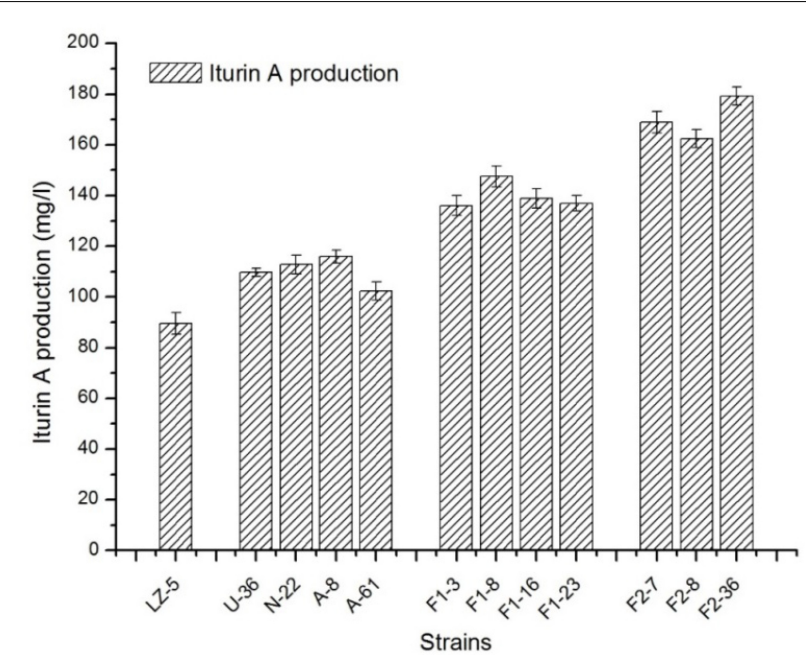

FIGURE 2 | The production of iturin A in different strains of B. amyloliquefaciens in landy medium. LZ-5, wild-type of B. amyloliquefaciens; $U, N, A$, the mutant strains of UV, NTG, and ARTP, respectively; F1, strains from the first round of genome shuffling; F2, strains from the second round of genome shuffling.
juice.The total soluble solids (TSS) were measured using a digital refractometer (WZS-1, Shanghai, China) and the TSS values were reported as ${ }^{o}$ Brix. The browning index was also determined using the previously reported method of Meydav et al. (1977).

\section{Statistical Analysis}

All of the experiments were repeated three times and each repetition was conducted in triplicate. For physico-chemical properties analysis, the results obtained were submitted to one way ANOVA $(p<0.05)$ using SPSS version 20. In the figures, data, and error bars represent arithmetic mean values and standard deviation, respectively.

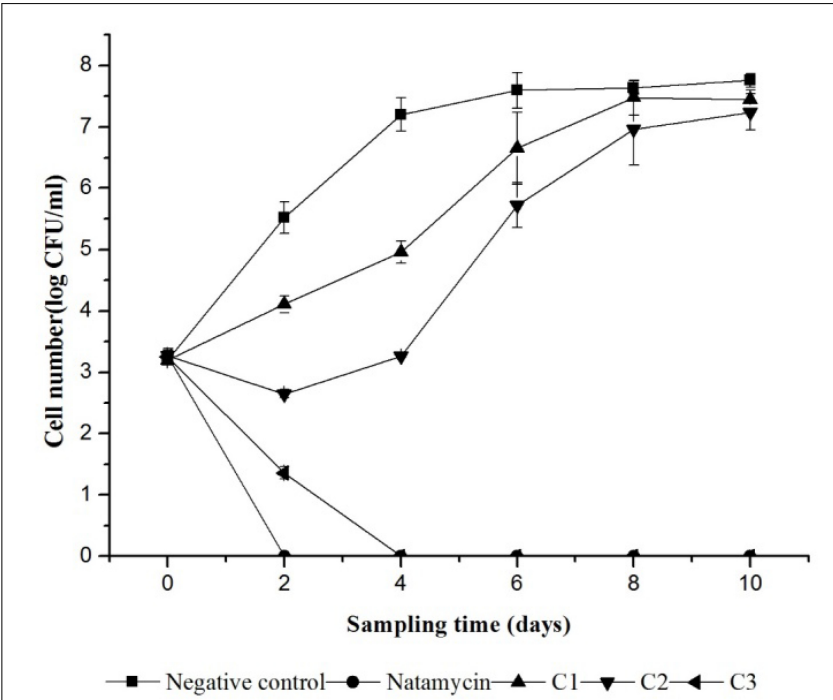

FIGURE 3 | Variation in viability of $S$. cerevisiae in orange juice during storage at $25^{\circ} \mathrm{C}$. Natamycin treatment at $0.3 \mathrm{mg} / \mathrm{ml}$; Negative control treated with sterile water. Iturin A treatment at $0.13 \mathrm{mg} / \mathrm{ml}(\mathrm{C} 1), 0.38 \mathrm{mg} / \mathrm{ml}(\mathrm{C} 2)$,and $0.76 \mathrm{mg} / \mathrm{ml}(\mathrm{C} 3)$

\section{RESULTS}

\section{Genome Shuffling of B. amyloliquefaciens for Improving Iturin A Production}

B. amyloliquefaciens LZ-5 isolated from Chinese honey was found strong anti-yeast activity. Then the anti-yeast compounds were separated and purified, and three substances were elucidated by HPLC-MS/MS. The positive ion mass spectrum analysis showed that $[\mathrm{M}+\mathrm{H}]^{+}$ion peaks were 1043.6, 1057.6, and 1071.6, respectively. And they were identified as to be Iturin A homolog, iturin $\mathrm{A} 2$, iturin $\mathrm{A} 3$, and iturin $\mathrm{A} 4$, with molecular weight of 1042.6, 1056.6, and 1070.6 Da (Figure 1). 
A

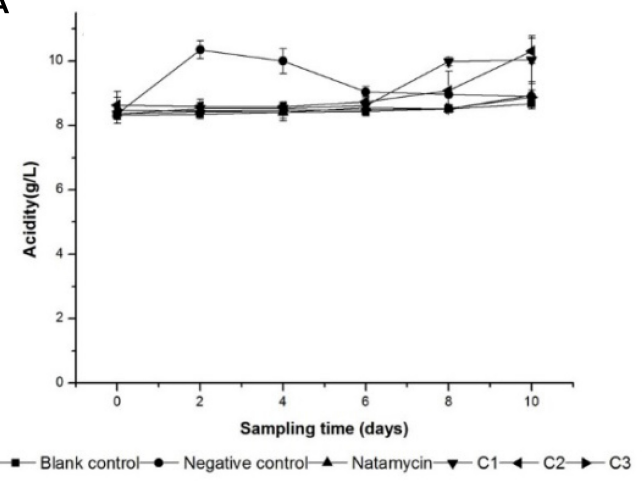

C

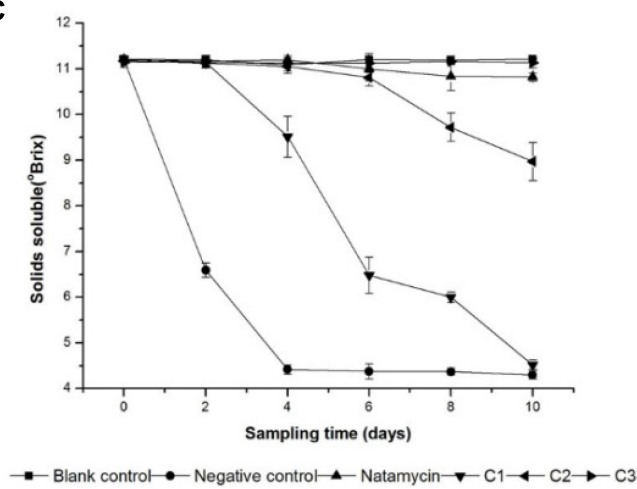

B

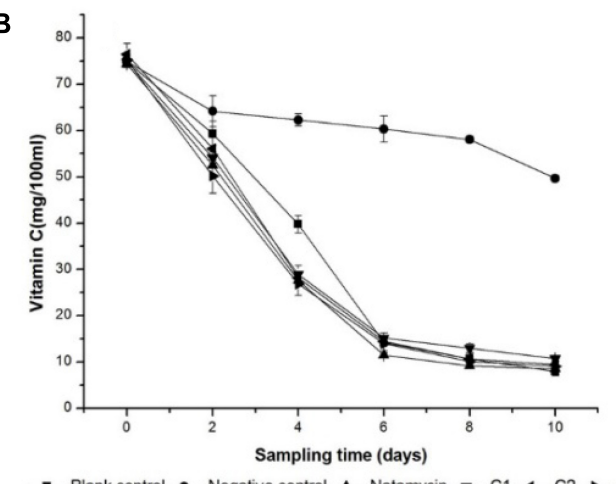

D

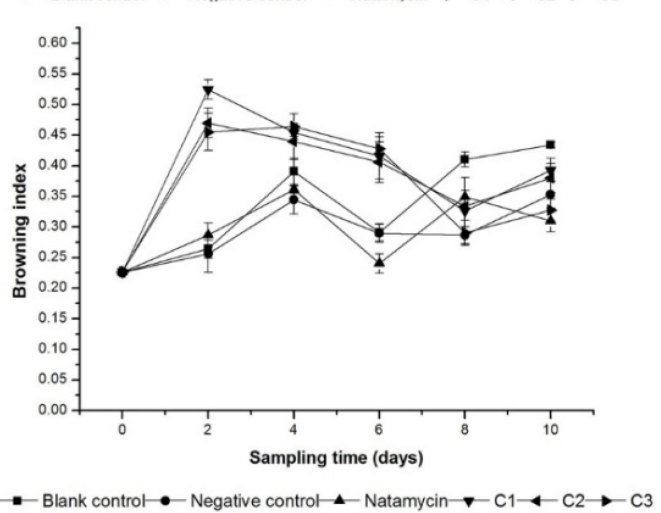

FIGURE 4 | Changes in Vitamin C (A),the total acidity (B),the total soluble solid (C), and browning index (D) of orange juice during storage at $25^{\circ} \mathrm{C}$. Natamycin with the concentration at $0.3 \mathrm{mg} / \mathrm{ml}$. Negative control and blank control treated with sterile water. iturin A treatment at $0.13 \mathrm{mg} / \mathrm{ml}$ (C1), $0.38 \mathrm{mg} / \mathrm{ml}$ (C2), and $0.76 \mathrm{mg} / \mathrm{ml}$ (C3).

To enhance the yield of iturin A, genome shuffling method was applied and two successive rounds of genome shuffling were carried out in this study. The four mutants of NTG, UV, and ARTP collected previously named U-36,N-22,A-8, A-61 were subjected to a first round of pool-wise recursive protoplast fusion. As shown in Figure 2, the production of iturin A was improved steadily after each turn of gene fusion. During the screening of the first generation, 325 colonies were picked out from the PDA medium with $0.6 \mathrm{~mol} / \mathrm{l}$ sodium chloride for the fermentation test. And four isolates F1-3, F1-8, F1-16, and F1-23 were selected for the detection of iturin A concentration by HPLC. Their iturin A production was in the range of $136.05 \sim 147.42 \mathrm{mg} / \mathrm{l}$, which was increased $51.9-64.68 \%$ as compared with the wild strains. And the four strains were used for the next shuffling. After the second shuffling, three isolates, F2-7, F2-8, and F2-36, with significantly increased iturin A production were obtained. The strain F236 exhibited $179.22 \mathrm{mg} / \mathrm{l}$ iturin A yield, which was a 2.03-fold increases compared to B. amyloliquefaciens LZ-5.

\section{Effect of Iturin A on Growth of Yeast in Orange Juice}

In order to evaluate the inactivation on S. cerevisiae by iturin A and the preservation of orange juice, samples were inoculated with spoilage organisms. Figure 3 shows the effect of different treatments on $S$. cerevisiae survival during storage at $25^{\circ} \mathrm{C}$. The initial count of yeast in different treatments ranged from 3.20 $\log \mathrm{cfu} / \mathrm{ml}$ to $3.28 \mathrm{log} \mathrm{cfu} / \mathrm{ml}$ except with the blank control which contain no treatment. The application of iturin A had a significant $(p<0.05)$ effect on the population of yeast in orange juice compared to the water as a control, in which the count of yeast reached $7.60 \log \mathrm{cfu} / \mathrm{ml}$ in 6 days. A complete inhibition was occurred in 4 days when the additive amount of iturin A was $0.76 \mathrm{mg} / \mathrm{ml}(\mathrm{C} 3)$. It is observed that yeast growth in the sample added with natamycin $(0.3 \mathrm{mg} / \mathrm{ml})$ and iturin $\mathrm{A}(0.76 \mathrm{mg} / \mathrm{ml})$ was fully inhibited. However, the inhibition effect was decreased gradually as the concentration of iturin A decreases (Figure 3).

\section{Physico-Chemical Properties of the Stored Orange Juice}

The physico-chemical properties can be used to evaluate the freshness of orange juice. Total titratable acidity, vitamin C, total soluble solids (TSS) and the browning index were monitored during the storage. As Figure $\mathbf{4 A}$ showed, the total titratable acidity had no significant $(p<0.05)$ difference in blank control, natamycin, and C3 after 10-days storage. There were varying degrees of increases between the other three groups because of acidic compound production by microbial fermentation. For example, the negative control incubated with yeast had a significant increase $(p<0.05)$ at the 2 nd day, and the yeast incubated in $\mathrm{C} 1$ and $\mathrm{C} 2$ started to reproduce resulting 
in a sudden increase $(p<0.05)$ of the total titratable acidity in the last 2 days. It can indicated that the existence of natamycin and $0.76 \mathrm{mg} / \mathrm{ml}$ iturin A inhibit the fermentation progress.

The vitamin $\mathrm{C}$ content reduced gradually as days of storage increased. In all samples, the reduction was ranged from $50 \sim 70 \%$ in different groups. The changes in vitamin $\mathrm{C}$ concentration during orange juice storage were analyzed and are depicted in Figure 4B. The rate of reduction of the sample treated with iturin $\mathrm{A}$ and natamycin was keep in pace with the blank control. This can indicate that there is no effect on the concentration of vitamin $\mathrm{C}$ in orange juice in the presence of iturin A. However, in the negative control, the reduction in vitamin C content was only $30 \%$ during the storage time, which was significantly $(p<0.05)$ lower than the other groups.

Figure 4C illustrates the variation of the total soluble solids $\left({ }^{\circ} \mathrm{Brix}\right)$ of the orange juice samples during storage in different treatments. The total soluble solids $\left({ }^{\circ} \mathrm{Brix}\right)$ is the reflection of sugar content to a large extent. And there was no significantly difference in groups with no microbial fermentation including the blank control, natamycin, and $\mathrm{C} 3$. In the sample treated with sterile water, the total soluble solids $\left({ }^{\circ}\right.$ Brix) was reduced $(p<0.05)$ to a lowest level at the 4 th day, and that of the other group treated with iturin $\mathrm{A}$ at a concentration of 0.38 and $0.13 \mathrm{mg} / \mathrm{ml}$ was also decreased $(p<0.05)$ to different degree.

When the browning index was analyzed after 10 days of storage, there was an increase $(p<0.05)$ in this index at the 2-days storage in the group treated with iturin A (Figure 4D). This change had nothing to do with the concentration of iturin A. In the end of the storage, there was no statistically significant difference $(p<0.05)$ observed between the samples. The presence of iturin A probably increased the rate of the browning reactions compared to the natamycin.

\section{DISCUSSION}

Genome shuffling is an efficient way for the evolution of new strains and the improvement of secondary metabolites. This strategy has been used in an attempt to enhance the production of fengycin and surfactin (Zhao et al., 2012, 2016). In this study, we utilized this advantage of genome shuffling to enhance the yield of iturin A in B. amyloliquefaciens with an increase of 2.03 -fold. Up to now, there is no relative report about application of genome shuffling in iturin A improvement. The traditional optimization strategy, often requires a considerable amount of work and time, and constantly fails to yield optimized conditions because it involves in more than one variable. Medium optimization of iturin A production has been carried out in solid-state fermentation using response surface methodology by Mizumoto and Shoda (2007), there was an 2.07-fold increase compared to the initial medium, but this satisfactory result was obtained through a great number of experiments and required a higher cost. However, genome shuffling amplifies genetic diversity by homologous recombination using protoplast fusion within the selected mutant population (Hida et al., 2007). By combining the three different kinds of mutagenesis which can effectively create more genetic variety (Zhao et al., 2012; Fang et al., 2013), the parent library with high productivity was established by using mutation-induced technique with UV, NTG, and ARTP in the work. Additionally, the successive improvement of the population was obtained by successive genome shuffling according to Patnaik et al. (2002), etc. Two successive rounds of gene shuffling were carried out in total with the efficiently screening strategies of agar diffusion. A new isolate (F2-36) exhibited significantly improved productivity of iturin A by 2.03-fold. Therefore, genome shuffling, based on the protoplast fusion involved in the whole genome, is more convenient and simple in the improvement of iturin A yield.

Considering the anti-yeast activity of iturin A, iturin A, obtained by acid precipitation from fermentation broth, was tested against $S$. cerevisiae to evaluate the inoculated orange juice. S. cerevisiae are major spoiled strains (Malcolm, 2006) in juice products, and the results of in vitro tests indicated that iturin A completely suppressed the growth of S. cerevisiae incubated in juice stored at $25^{\circ} \mathrm{C}$ with a concentration of $0.76 \mathrm{mg} / \mathrm{ml}$ at the 4 th day, which was similar to the efficiency treated with $0.3 \mathrm{mg} / \mathrm{ml}$ natamycin. To our best knowledge, limited report was found about this natural compound tested in vivo as a preservative to reduce yeast contamination. But for seeking for an alternative of chemical additives, some other kinds of natural product have been studied. Among them, lemon grass oil at $1.13 \mathrm{mg} / \mathrm{ml}$ exerted complete growth inhibition of S. cerevisiae in mixed fruit juice (Tyagi et al., 2014), and the MFC of Eucalyptus globulus oil against S. cerevisiae was $2.25 \mathrm{mg} / \mathrm{ml}$ (Tyagi and Malik, 2011), etc. These natural compounds have different levels of inhibition effect on the yeast cell, and the extent of inhibition increases with increasing concentration of all natural compounds. Whereas iturin A from a microorganism is easier to achieve an efficient production than from the extraction of plants, so its application in food is more potential.

The physical-chemical parameters are the most representative to characterize the orange juice. In this study, the total acidity, vitamin $\mathrm{C}$, the total soluble solid and the browning index were monitored during the storage of the orange juice. The total acidity and the total soluble solid nearly had no change in the 10days storage at $25^{\circ} \mathrm{C}$ after $\mathrm{C} 3$ treated with iturin $\mathrm{A}$. This result was in accordance with the previous study (de Oliveira Junior et al., 2015), where there was no changes in total acidity in juice without fermentation progress. Yeast growth can remove a small proportion of the sugars in a fruit juice (Malcolm, 2006), which is closely related to the amount of the total soluble solid. Therefore, subtle changes have been observed in juice added with iturin A in comparison to the negative control. Vitamin C loss follows a linear equation by applying a regression analysis with increasing storage time on account of oxidative enzyme reaction (Lee and Coates, 1999). This gives a suitable explanation to our result that the content of vitamin $\mathrm{C}$ was decreased in all samples during 10-days storage. Regarding to the browning index, there is hardly any significant difference among these groups. 


\section{CONCLUSION}

This study demonstrates that the gene shuffling is an effective method to accelerate the evolution of strains by improving the iturin A production in B. amyloliquefaciens. Furthermore, we introduced the antimicrobial lipopeptide in the preservation of juice product for the first time. The experimental evidence shows that all concentrations of iturin A have an effect against the S. cerevisiae incubated in orange juice, without hardly changing the physical and chemical properties of the sample. The iturin A has the potential as an additive to control the yeast contamination in juice products. Further research should be pursued in order to investigate the impact of iturin A on human and animal cell lines.

\section{REFERENCES}

Aznar, A., Fernandez, P. S., Periago, P. M., and Palop, A. (2015). Antimicrobial activity of nisin, thymol, carvacrol and cymene against growth of Candida lusitaniae. Food Sci. Technol. Int. 21, 72-79. doi: 10.1177/1082013213514593

Bevilacqua, A., Campaniello, D., Sinigaglia, M., and Corbo, M. R. (2015). Combination of ultrasound and antimicrobial compounds towards Pichia spp. and Wickerhamomyces anomalus in pineapple juice. LWT Food Sci. Technol. 64, 616-622. doi: 10.1016/j.lwt.2015.06.038

Bie, X. M., Lu, Z. X., Lu, F. X., and Zeng, X. X. (2005). Screening the main factors affecting extraction of the antimicrobial substance from Bacillus $\mathrm{sp}$ fmbJ using the Plackett-Burman method. World J. Microbiol. Biotechnol. 21, 925-928. doi: 10.1007/s11274-004-6722-z

Biot-Pelletier, D., and Martin, V. J. J. (2014). Evolutionary engineering by genome shuffling. Appl. Microbiol. Biotechnol. 98, 3877-3887. doi: 10.1007/s00253-0145616-8

Cho, K. M., Math, R. K., Hong, S. Y., Islam, S. M. A., Mandanna, D. K., Cho, J. J., et al. (2009). Iturin produced by Bacillus pumilus HY1 from Korean soybean sauce (kanjang) inhibits growth of aflatoxin producing fungi. Food Control 20, 402-406. doi: 10.1016/j.foodcont.2008.07.010

de Oliveira Junior, A. A., de Araujo Couto, H. G., Barbosa, A. A., Carnelossi, M. A., and de Moura, T. R. (2015). Stability, antimicrobial activity, and effect of nisin on the physico-chemical properties of fruit juices. Int. J. Food Microbiol. 211, 38-43. doi: 10.1016/j.ijfoodmicro.2015.06.029

Fang, M. Y., Jin, L. H., Zhang, C., Tan, Y. Y., Jiang, P. X., Ge, N., et al. (2013). Rapid mutation of Spirulina platensis by a new mutagenesis system of atmospheric and room temperature plasmas (ARTP) and generation of a mutant library with diverse phenotypes. PLoS One 8:e77046. doi: 10.1371/journal.pone.00 77046

Grau, A., Ortiz, A., Godos, A., and Gomez-Fernandez, J. C. (2000). A biophysical study of the interaction of the lipopeptide antibiotic iturin A with aqueous phospholipid bilayers. Arch. Biochem. Biophys. 377, 315-323. doi: 10.1006/abbi. 2000.1791

Hida, H., Yamada, T., and Yamada, Y. (2007). Genome shuffling of Streptomyces sp U121 for improved production of hydroxycitric acid. Appl. Microbiol. Biotechnol. 73, 1387-1393. doi: 10.1007/s00253-006-0613-1

John, R. P., Gangadharan, D., and Nampoothiri, K. M. (2008). Genome shuffling of Lactobacillus delbrueckii mutant and Bacillus amyloliquefaciens through protoplasmic fusion for L-lactic acid production from starchy wastes. Bioresour. Technol. 99, 8008-8015. doi: 10.1016/j.biortech.2008. 03.058

Kanlayavattanakul, M., and Lourith, N. (2010). Lipopeptides in cosmetics. Int. J. Cosmet. Sci. 32, 1-8. doi: 10.1111/j.1468-2494.2009.00543.x

Labbani, F.-Z. K., Turchetti, B., Bennamoun, L., Dakhmouche, S., Roberti, R., Corazzi, L., et al. (2015). A novel killer protein from Pichia kluyveri isolated from an Algerian soil: purification and characterization of its in vitro activity against food and beverage spoilage yeasts. Antonie Van Leeuwenhoek 107, 961-970. doi: 10.1007/s10482-015-0388-4

\section{AUTHOR CONTRIBUTIONS}

ZL designed the research. JS, XZ, and YL performed the research. JS, XZ, YL, HZ, and FL analyzed the data. ZL and JS wrote the paper.

\section{FUNDING}

This work was supported by the National Natural Science Foundation of China (No. 31571887), Agricultural Innovation Foundation of Jiangsu Provice (CX 16-1058), and Jiangsu Collaborative Innovation Center of Meat Production and Processing (2011 plan).

Leclere, V., Bechet, M., Adam, A., Guez, J. S., Wathelet, B., Ongena, M., et al. (2005). Mycosubtilin overproduction by Bacillus subtilis BBG100 enhances the organism's antagonistic and biocontrol activities. Appl. Environ. Microbiol. 71, 4577-4584. doi: 10.1128/AEM.71.8.4577-4584.2005

Lee, H. S., and Coates, G. A. (1999). Vitamin C in frozen, fresh squeezed, unpasteurized, polyethylene-bottled orange juice: a storage study. Food Chem. 65, 165-168. doi: 10.1016/S0308-8146(98)00180-0

Li, S. B., Qian, Y., Liang, Z. W., Guo, Y., Zhao, M. M., and Pang, Z. W. (2016). Enhanced butanol production from cassava with Clostridium acetobutylicum by genome shuffling. World J. Microbiol. Biotechnol. 32:53. doi: 10.1007/s11274016-2022-7

Loredo, A. B. G., Guerrero, S. N., and Alzamora, S. M. (2015). Inactivation kinetics and growth dynamics during cold storage of Escherichia coli ATCC 11229, Listeria innocua ATCC 33090 and Saccharomyces cerevisiae KE162 in peach juice using aqueous ozone. Innov. Food Sci. Emerg. Technol. 29, 271-279. doi: 10.1016/j.ifset.2015.02.007

Malcolm, S. (2006). "Food and beverage spoilage yeasts," in Yeasts in Food \& Beverages, eds A. Querol and G. Fleet (Berlin: Springer), 335-379.

Mandal, S. M., Barbosa, A. E. A. D., and Franco, O. L. (2013). Lipopeptides in microbial infection control: scope and reality for industry. Biotechnol. Adv. 31, 338-345. doi: 10.1016/j.biotechadv.2013.01.004

Masamba, K. G., and Nguyen, M. (2008). Determination and comparison of vitamin $\mathrm{C}$, calcium and potassium in four selected conventionally and organically grown fruits and vegetables. Afr. J. Biotechnol. 7, 2915-2919.

Meena, K. R., and Kanwar, S. S. (2015). Lipopeptides as the antifungal and antibacterial agents: applications in food safety and therapeutics. Biomed. Res. Int. 2015:473050. doi: 10.1155/2015/473050

Meydav, S., Saguy, I., and Kopelman, I. J. (1977). Browning determination in citrus products. J. Agr. Food Chem. 25, 602-604. doi: 10.1021/jf60211a030

Mhammedi, A., Peypoux, F., Besson, F., and Michel, G. (1982). Bacillomycin F, a new antibiotic of iturin group: isolation and characterization. J. Antibiot. 35, 306-311. doi: 10.7164/antibiotics.35.306

Mizumoto, S., and Shoda, M. (2007). Medium optimization of antifungal lipopeptide, iturin A, production by Bacillus subtilis in solid-state fermentation by response surface methodology. Appl. Microbiol. Biotechnol. 76, 101-108. doi: 10.1007/s00253-007-0994-9

Mulligan, C. N., Yong, R. N., and Gibbs, B. F. (2001). Heavy metal removal from sediments by biosurfactants. J. Hazard. Mater. 85, 111-125. doi: 10.1016/S03043894(01)00224-2

Nitschke, M., and Costa, S. G. V. A. O. (2007). Biosurfactants in food industry. Trends Food Sci. Technol. 18, 252-259. doi: 10.1016/j.tifs.2007.01.002

Patnaik, R., Louie, S., Gavrilovic, V., Perry, K., Stemmer, W. P. C., Ryan, C. M., et al. (2002). Genome shuffling of Lactobacillus for improved acid tolerance. Nat. Biotechnol. 20, 707-712. doi: 10.1038/nbt0702-707

Peter, A., Nicula, C., Mihaly-Cozmuta, A., Mihaly-Cozmuta, L., and Indrea, E. (2012). Chemical and sensory changes of different dairy products during storage in packages containing nanocrystallised TiO2. Int. J. Food Sci. Technol. 47, 1448-1456. doi: 10.1111/j.1365-2621.2012.02992.x 
Samani, B. H., Khoshtaghaza, M. H., Lorigooini, Z., Minaei, S., and Zareiforoush, H. (2015). Analysis of the combinative effect of ultrasound and microwave power on Saccharomyces cerevisiae in orange juice processing. Innov. Food Sci. Emerg. Technol. 32, 110-115. doi: 10.1016/j.ifset.2015. 09.015

Schaller, K. D., Fox, S. L., Bruhn, D. F., Noah, K. S., and Bala, G. A. (2004). Characterization of surfactin from Bacillus subtilis for application as an agent for enhanced oil recovery. Appl. Biochem. Biotechnol. 113, 827-836. doi: 10. 1385/ABAB:115:1-3:0827

Snoek, T., Nicolino, M. P., Van den Bremt, S., Mertens, S., Saels, V., Verplaetse, A., et al. (2015). Large-scale robot-assisted genome shuffling yields industrial Saccharomyces cerevisiae yeasts with increased ethanol tolerance. Biotechnol. Biofuels 8:32. doi: 10.1186/s13068-015-0216-0

Tyagi, A. K., Gottardi, D., Malik, A., and Guerzoni, M. E. (2013). Anti-yeast activity of mentha oil and vapours through in vitro and in vivo (real fruit juices) assays. Food Chem. 137, 108-114. doi: 10.1016/j.foodchem.2012.10.015

Tyagi, A. K., Gottardi, D., Malik, A., and Guerzoni, M. E. (2014). Chemical composition, in vitro anti-yeast activity and fruit juice preservation potential of lemon grass oil. LWT Food Sci. Technol. 57, 731-737. doi: 10.1016/j.lwt.2014. 02.004

Tyagi, A. K., and Malik, A. (2010). Liquid and vapour-phase antifungal activities of selected essential oils against Candida albicans: microscopic observations and chemical characterization of Cymbopogon citratus. BMC Complement. Altern. Med. 10:65. doi: 10.1186/1472-6882-10-65

Tyagi, A. K., and Malik, A. (2011). Antimicrobial potential and chemical composition of Eucalyptus globulus oil in liquid and vapour phase against food spoilage microorganisms. Food Chem. 126, 228-235. doi: 10.1016/j.foodchem. 2010.11 .002
Zhang, G. Q., Lin, Y. P., Qi, X. N., Wang, L. X., He, P., Wang, Q. H., et al. (2015). Genome shuffling of the nonconventional yeast Pichia anomala for improved sugar alcohol production. Microb. Cell Fact. 14:112. doi: 10.1186/s12934-0150303-8

Zhang, Y. X., Perry, K., Vinci, V. A., Powell, K., Stemmer, W. P., and del Cardayre, S. B. (2002). Genome shuffling leads to rapid phenotypic improvement in bacteria. Nature 415, 644-646. doi: 10.1038/415644a

Zhao, J. F., Li, Y. H., Zhang, C., Yao, Z. Y., Zhang, L., Bie, X. M., et al. (2012). Genome shuffling of Bacillus amyloliquefaciens for improving antimicrobial lipopeptide production and an analysis of relative gene expression using FQ RT-PCR. J. Ind. Microbiol. Biotechnol. 39, 889-896. doi: 10.1007/s10295-0121098-9

Zhao, J. F., Zhang, C., Lu, J., and Lu, Z. X. (2016). Enhancement of fengycin production in Bacillus amyloliquefaciens by genome shuffling and relative gene expression analysis using RT-PCR. Can. J. Microbiol. 62, 431-436. doi: 10.1139/ cjm-2015-0734

Conflict of Interest Statement: The authors declare that the research was conducted in the absence of any commercial or financial relationships that could be construed as a potential conflict of interest.

Copyright (C) $2018 \mathrm{Shi}, \mathrm{Zhu}, \mathrm{Lu}, \mathrm{Zhao}, \mathrm{Lu}$ and Lu. This is an open-access article distributed under the terms of the Creative Commons Attribution License (CC BY). The use, distribution or reproduction in other forums is permitted, provided the original author(s) and the copyright owner(s) are credited and that the original publication in this journal is cited, in accordance with accepted academic practice. No use, distribution or reproduction is permitted which does not comply with these terms. 